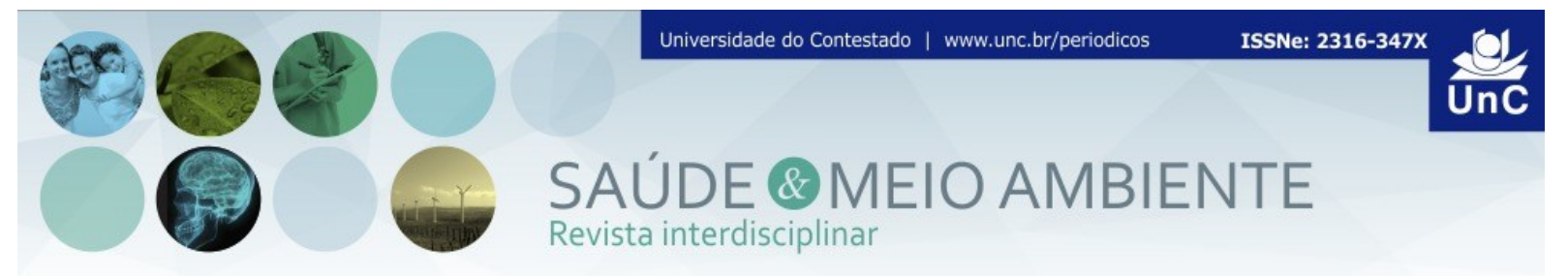

\title{
REPRESENTAÇÕES SOCIAIS DA POBREZA PARA ADOLESCENTES DE UM MUNICÍPIO DO INTERIOR DO ESTADO DE SANTA CATARINA
}

Pollyana Weber da Maia Pawlowytsch ${ }^{1}$

Jerusa Shmidt ${ }^{2}$

\begin{abstract}
RESUMO
A crescente desigualdade social e econômica tem se mostrado cada vez mais evidente nos dias atuais e também se posicionado como característica da exclusão social no mundo todo. A adolescência é a fase em que se está mais propicio à crises e sofrimentos e com isso é comum que os adolescentes sintam-se discriminados pela falta de dinheiro. O objetivo deste estudo foi Identificar quais são as representações que adolescentes do interior do estado de Santa Catarina possuem sobre a pobreza. A coleta de dados foi realizada com 35 adolescentes de uma escola do interior de Santa Catarina a partir de um questionário com questões abertas e fechadas. Os resultados apontam que parte dos adolescentes entrevistados diz saber o que é pobreza a partir de uma percepção de que a mesma é a falta de dinheiro e bens materiais. Um grupo relevante de participantes do estudo se consideram pobres a partir de sua compreensão de pobreza. Devido aos adolescentes encontrar-se em uma fase de desenvolvimento onde muitas mudanças físicas, psicológicas e sociais acontecem, identificar sua interpretação sobre esta realidade social pôde não só contribuir para um melhor entendimento do mesmo sobre esta realidade social como também ofereceu ao ambiente científico informações sobre uma leitura diferenciada dos aspectos sociais da pobreza visualizada pelo sujeito que vivencia e pelo sujeito que observa sua dinâmica.
\end{abstract}

Palavras-Chave: Adolescência. Pobreza. Representações Sociais.

\footnotetext{
${ }^{1}$ Mestre em Desenvolvimento Regional pela Universidade do Contestado. Professora Titular da Universidade do Contestado Campus Mafra, Santa Catarina. Brasil. E-mail: pollyana@netuno.com.br

${ }^{2}$ Aadêmica de Psicologia da Universidade do Contestado - Campus Mafra. Santa Catarina. Brasil. Email: jerusapva@hotmail.com
} 


\title{
SOCIAL REPRESENTATIONS OF POVERTY FOR ADOLESCENTS OF A MUNICIPALITY OF THE INTERIOR OF THE STATE OF SANTA CATARINA
}

\begin{abstract}
The growing social and economic inequality has proven increasingly evident nowadays and also positioned itself as a characteristic of social exclusion worldwide. Adolescence is the stage that is most conducive to crises and suffering and it is common for teenagers to feel discriminated against by lack of money. The objective of this study was to identify what are the representations that teenagers in the state of Santa Catarina have on poverty. Data collection was carried out with 35 students of a school in the interior of Santa Catarina from a questionnaire with open and closed questions. The results show that some of the teens surveyed says he knows what poverty from a perception that it is the lack of money and material goods. An important group of study participants consider themselves poor from their understanding of poverty. Because adolescents find themselves in a phase of development where many physical, psychological and social changes take place, identify their interpretation of this social reality could not only contribute to a better understanding of it on this social reality but also offered the scientific environment information a differentiated reading of the social aspects of poverty displayed by the subject who experiences and the guy who watches his momentum.
\end{abstract}

Keywords: Adolescence. Poverty. Social Representations.

\section{INTRODUÇÃO}

A pobreza e a desigualdade social contêm índices que sempre se fizeram presentes no processo histórico da sociedade de forma recorrente, nas diferentes gerações e que vem persistindo e se expandindo até os dias atuais. Na atualidade a problemática da pobreza tem atraído e preocupações de nível mundial de forma que, estudos sobre a desigualdade de renda, a inclusão e exclusão social têm se mostrado temas cada vez mais centrais. Ao se estudar a pobreza verifica-se que ela já existe há muitos anos na história da humanidade e com o passar do tempo verificam-se transformações quanto a sua configuração, a maneira como é pensada e as ações que ocorreram com vistas ao seu tratamento (CRESPO; GUROVITZ, 2002).

Ao pensar nestes estudos e transformações a pobreza pode ser entendida sob diversos aspectos, como privação em termos de materiais, na forma de fome ou na baixa qualidade de moradia, tratando-se de termos econômicos, pode ser entendida sob forma de inadequação de renda e em termos sociais é definida como isolamento da comunidade ou sentimento de baixa autoestima (VINHAIS, 2006).

Já as transformações ocorridas na política econômica do Brasil produziram profundas mudanças na vida econômica, social e cultural da população, gerando altos 
índices de desigualdades sociais e de renda da população, afetando as suas condições de sobrevivência e minando as expectativas de superação desse estado de pobreza, reforçando sua submissão aos serviços públicos existentes (SANTANA, 2012). Frente a isso Wlodarski e Cunha (2005) afirmam que a desigualdade social no Brasil se deve ao fato da má distribuição de recursos, pois pode ser considerado um país rico, porém possui um dos maiores índices de desigualdade do mundo. $\mathrm{E}$ consideram ainda que "neste sentido, a pobreza é vista como decorrente da desigualdade social, acompanhando o processo de agravamento desta" (WLODARSKI; CUNHA, 2005 p. 7).

A desigualdade antecede a exclusão social e frente a isso Lopes (2006 p.1) afirma que "a exclusão social produz uma nova forma de controle social". O termo exclusão social é uma construção teórica formulada a partir do conceito de vulnerabilidade social, tendo num primeiro momento, se apresentado como referencia para a caracterização de situações sociais limites, de pobreza ou marginalidade, e para a consequente formulação de políticas públicas voltadas para o enfrentamento destas questões (SANTANA, 2012).

A partir dos conceitos de pobreza, desigualdade e exclusão social surgem as representações sociais que são resultantes de articulações geradoras de sentido e não elementos discretos. De outra forma, estaríamos tomando as partes como o todo, o que as desvirtuaria, reduzindo-as à estagnação. A abrangência envolvida é, portanto, condição de particularização, porque é, através dela, que o sentido de um objeto se estrutura. Moscovici lembra que, se "nós as isolarmos e as separarmos umas das outras e de suas instituições, não nos restarão senão fragmentos de realidade desvitalizada, reduzida a sua expressão mais simples" (MOSCOVICl, 2003, p.76).

O estudo das representações sociais provoca uma releitura do senso comum, do saber popular, do conhecimento do cotidiano e do conhecimento pré-teórico de forma que o conhecimento sobre a realidade torne-se socialmente construído. Esta construção se dá a partir do saber do sujeito interligado com a sua inscrição social. Sobre isso Moscovicci (1961) dá o nome de processo social (ARRUDA, 2002).

Sendo assim estudar a Teoria das Representações Sociais na interface da ciência social, sobre aspectos psicológicos e sociológicos, tem se mostrado uma alternativa de plasticidade em busca da compreensão de fenômenos sociais, uma vez que estes são móveis e voláteis (OLIVEIRA, 2004).

Quando se fala que a pobreza está presente nas famílias, de fato lembra-se que o adolescente está inserido ou veio deste núcleo primário. Para Papalia; Olds e Feldman (2010) a adolescência começa com a puberdade, onde acontecem importantes alterações sendo elas físicas, emocionais, cognitivas e psicossociais inter-relacionadas $\mathrm{A}$ adolescência é o período que se compreende entre doze e vinte e cinco anos. Stanley Hall (1844-1924) descreveu-a como sendo um período de crises, pois este havia sofrido a retirada o paraíso da vida da infância. A partir dessa teoria muitos teóricos têm formulado novos estudos sobre a adolescência, porém vêm se detendo a pensar que esse período é gerador de crises e sofrimentos (MAAKAROUN, 2006). 
Para compreender as condições de sobrevivência de crianças e adolescentes pobres no Brasil e no mundo, é necessário restituir as análises socioeconômicas e culturais de existência centrada nas relações sociais de classe e de gênero. Nos últimos vinte anos a problemática das crianças e adolescentes desfavorecidas no Brasil e no âmbito internacional é objeto de discussão de pesquisas das Ciências Sociais objetivando propiciar a construção de um conhecimento com vistas à erradicação da mesma (MACÊDO, 2014).

\section{MATERIAIS E MÉTODOS}

A pesquisa foi de natureza básica, exploratória e descritiva de abordagem mista - qualitativa e quantitativa. O estudo foi realizado em uma escola no planalto norte catarinense, na cidade de Mafra/SC. Para compor a população, foi selecionada uma amostra aleatória, onde todos os adolescentes foram convidados a participar da pesquisa, porém apenas 35 destes atenderam aos requisitos mínimos para a participação, que foram: estar devidamente matriculado e frequentando as aulas, ter idade até 25 anos, e assinar ou trazer assinado pelos pais o Termo de Consentimento Livre e esclarecido (TCLE).

Após os adolescentes assinarem o TCLE (maiores de 18 anos) ou trazerem o mesmo assinado pelos pais (menores de 18 anos) foi entregue um questionário com 12 questões abertas e fechadas, composto com dados sócio-demográficos e também com questões acerca do entendimento da pobreza para os adolescentes.

A análise de dados quantitativos se deu a partir de tabulação de dados e tratamento estatístico que posteriormente foram relacionados e discutidos com a literatura relevante à temática abordada para obter significância e serem validados. Os dados qualitativos foram analisados a partir de categorização de respostas.

\section{RESULTADOS E DISCUSSÕES}

Fizeram parte do estudo 35 adolescentes de uma escola da cidade de Mafra/SC. Os dados sociodemográficos são destacados na tabela 1 abaixo: 
Tabela 1 - Dados Sociodemográficos

\begin{tabular}{|c|c|c|c|c|c|c|c|}
\hline \multicolumn{2}{|c|}{ Gênero } & \multicolumn{2}{|c|}{ Idade } & \multicolumn{2}{|c|}{$\begin{array}{l}\text { Trabalhando } \\
\text { Atualmente }\end{array}$} & \multicolumn{2}{|c|}{ Renda Familiar } \\
\hline \multirow{4}{*}{ Feminino } & \multirow{4}{*}{26} & 16 Anos & 1 & \multirow{4}{*}{ Sim } & \multirow{4}{*}{26} & \multirow{2}{*}{$\begin{array}{c}\text { Inferior a } 1 \\
\text { salário Mínimo }\end{array}$} & \multirow{2}{*}{1} \\
\hline & & 17 Anos & 9 & & & & \\
\hline & & 18 Anos & 13 & & & \multirow{2}{*}{1 Salário Mínimo } & \multirow{2}{*}{7} \\
\hline & & 19 Anos & 4 & & & & \\
\hline \multirow{5}{*}{ Masculino } & \multirow{5}{*}{9} & 20 Anos & 2 & \multirow{5}{*}{ Não } & \multirow{5}{*}{9} & \multirow{2}{*}{$\begin{array}{l}2 \text { Salários } \\
\text { Mínimos }\end{array}$} & \multirow{2}{*}{12} \\
\hline & & 21 Anos & 3 & & & & \\
\hline & & 22 Anos & 1 & & & \multirow{3}{*}{$\begin{array}{c}\text { Superior a } 2 \\
\text { Salários Mínimos }\end{array}$} & \multirow{3}{*}{15} \\
\hline & & 23 Anos & 1 & & & & \\
\hline & & 24 Anos & 1 & & & & \\
\hline
\end{tabular}

Fonte: Dados do Estudo (2015)

No quadro acima pode-se observar que participaram do estudo 26 adolescentes do gênero feminino e 9 do gênero masculino. A idade que mais prevaleceu foi 18 anos seguindo a idade de 17 anos. Dos adolescentes entrevistados 26 possuem trabalho fixo atualmente e a renda familiar que mais aparece fica entre 2 salários mínimos e superior a 2 salários mínimos. Alguns destes adolescentes não moram mais com os pais, e o salário que recebem é para se manterem sozinhos fora de casa. Os que ainda estão inserido no núcleo familiar participam do orçamento, contribuindo para a estabilidade financeira. Woleck (2002) relata que a população brasileira conta com o emprego para sua única fonte de renda, e com isso é a única forma de sobrevivência.

Quando os adolescentes foram questionados se sabiam o que é pobreza, $82,8 \%$ dos participantes disseram saber o significa pobreza, enquanto $14,2 \%$ disseram não saber, como mostra o gráfico 1 a seguir:

Gráfico 1 - Adolescentes que sabem o que é pobreza

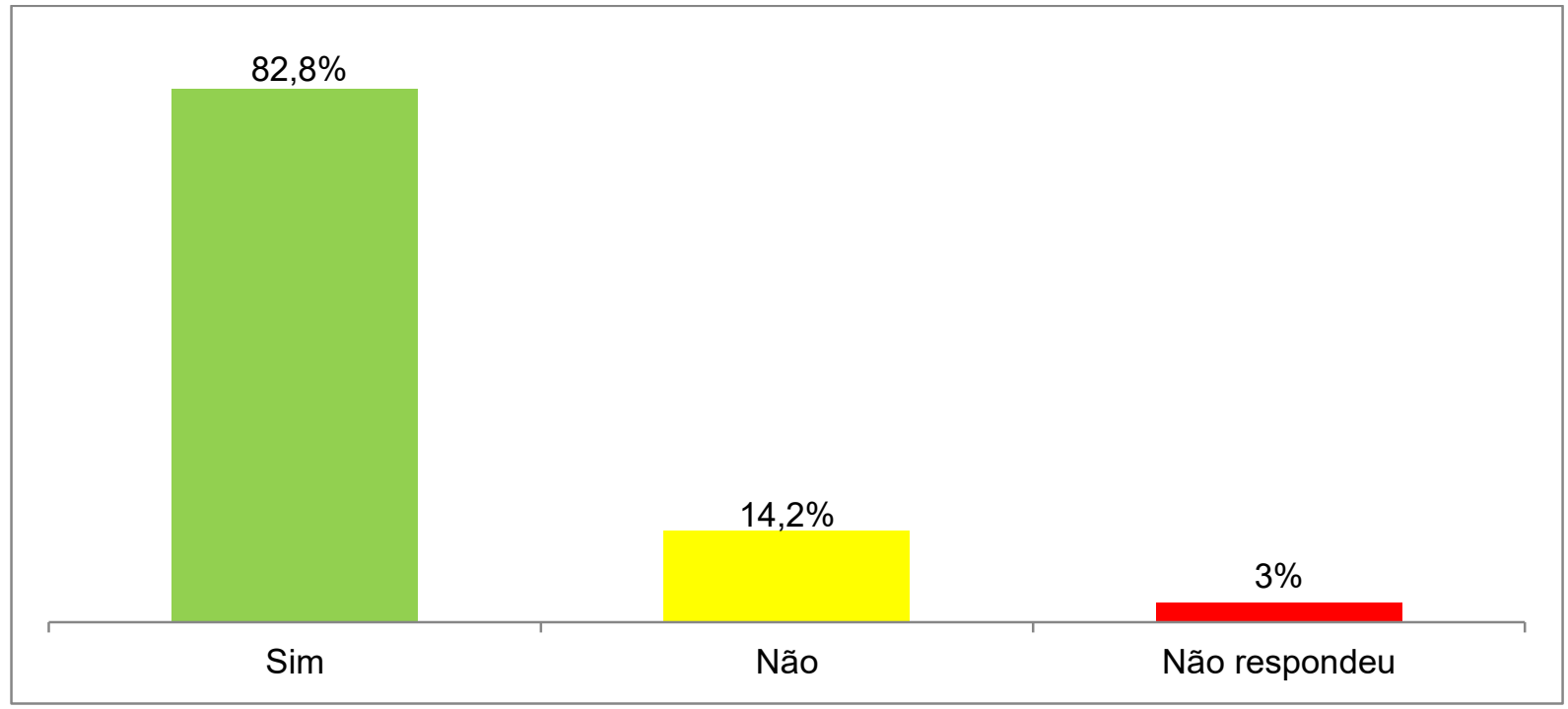

Fonte: Dados do Estudo (2015) 
Representações sociais da pobreza para adolescentes de um município do interior do estado de Santa Catarina

No que diz respeito aos conceitos dados pelos adolescentes sobre pobreza, esta seria a falta de algum bem material, ou seja, moradia, roupas, comida, etc. não levando em consideração a pobreza cultural, de valores e social vivida em nosso país. Como mostram as afirmações no quadro 1 :

Quadro 1 - Conceitos de Pobreza dos Adolescentes Entrevistados

\begin{tabular}{|l|l|}
\hline SIC & Verbalização \\
\hline SIC 8 & $\begin{array}{l}\text { "É não ter comida, não ter água encanada, uma moradia, dinheiro para gastar no que } \\
\text { quiser". }\end{array}$ \\
\hline SIC 14 & $\begin{array}{l}\text { "Pobreza é você não ter dinheiro o suficiente para poder sustentar sua própria familia } \\
\text { ou o dinheiro não chegar para pagar as dividas." }\end{array}$ \\
\hline SIC 17 & $\begin{array}{l}\text { "Não ter uma alimentação, não ter residência fixa, e ter que depender da vontade dos } \\
\text { outros". }\end{array}$ \\
\hline SIC 35 & $\begin{array}{l}\text { "A pobreza para mim é não ter o que comer, não ter um lar para morar e roupas para } \\
\text { vestir e calçados bons para usar." }\end{array}$ \\
\hline
\end{tabular}

Fonte: Dados do Estudo (2015)

Para Crespo e Gurovitz (2002) definir pobreza é algo muito complexo, pois esta definição pode ser feita a partir de algum juízo de valor, em aspectos relativos ou absolutos. A pobreza pode ser estudada apenas do ponto de vista econômico, mas também pode estar associada a aspectos não econômicos. Sendo analisada de forma dependente ou independente da estrutura sociopolítica da sociedade.

A partir do pressuposto de que os adolescentes sabiam o que é pobreza foi questionado se eles se consideram pobres e $82,9 \%$ deles disse que não, enquanto que $17,1 \%$ se considera pobre dentro de sua compreensão de pobreza como revela o gráfico 2 :

Gráfico 2 - Adolescentes que se consideram pobres

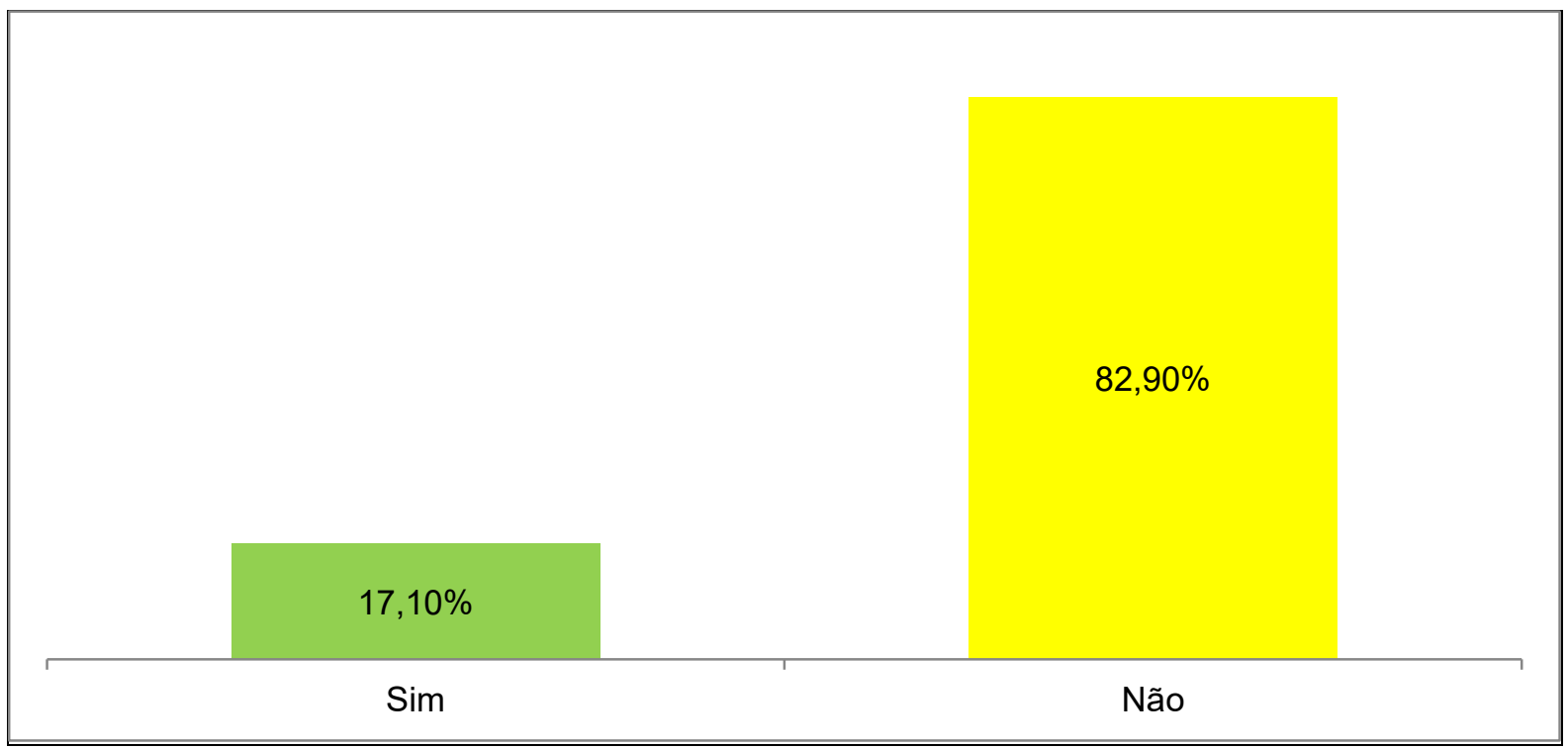

Fonte: Dados do Estudo (2015) 
Quando se menciona a compreensão dos adolescentes sobre a pobreza, onde os mesmos mencionam a privação de bens materiais podemos associar Crespo e Gurovicz (2002) afirmando que a noção de pobreza refere-se a algum tipo de privação, seja ele material cultural ou social, em face aos recursos disponíveis de uma pessoa ou família.

Foi constatado ainda que $62,8 \%$ dos adolesces entrevistados acredita que a condição da pobreza interfere nos relacionamentos interpessoais, sejam estes afetivos, de trabalho ou de amizade como destaca o gráfico 3:

Gráfico 3 - Adolescentes que acreditam que a pobreza interfere nos relacionamentos interpessoais

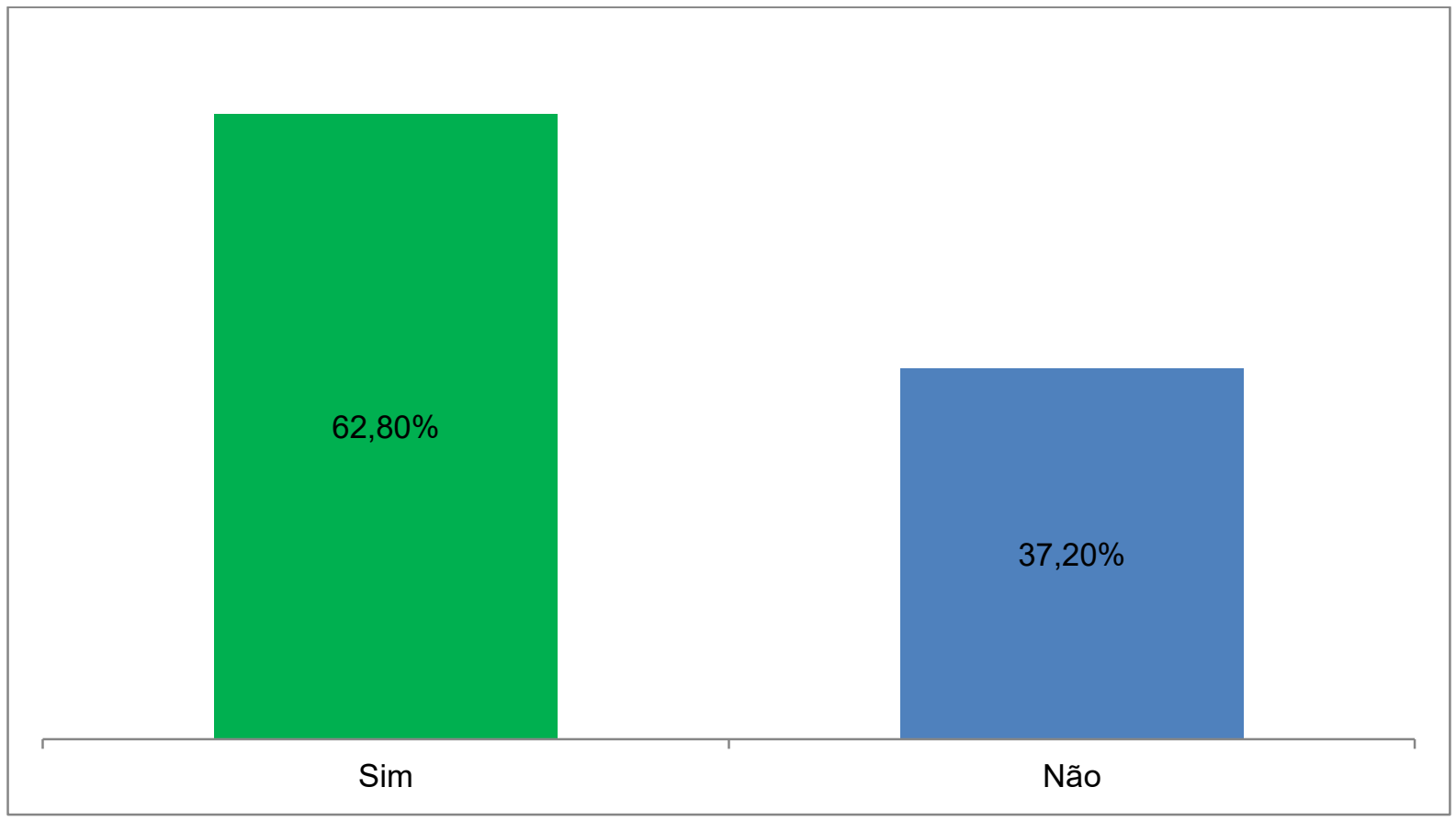

Fonte: Dados do Estudo (2015)

Os adolescentes que responderam não acreditar que a pobreza possa intervir justificam dizendo que a pobreza não pode definir quem você é ou deixa de ser em relação ao seu caráter e atitudes, como apresenta o quadro a seguir:

Quadro 2 - A pobreza como influência nos relacionamentos interpessoais

\begin{tabular}{|l|l|}
\hline SIC & Verbalização \\
\hline SIC 5 & $\begin{array}{l}\text { "Sim. Porque ainda tem pessoas que diferenciam umas pessoas das outras pela sua } \\
\text { questão financeira". }\end{array}$ \\
\hline SIC 10 & "Sim. Pela aparência, e por não ter nada, o preconceito é enorme, infelizmente". \\
\hline SIC 28 & $\begin{array}{l}\text { "Sim. Porque a sociedade discrimina muito as pessoas que vivem na pobreza. O } \\
\text { costume de julgar pela aparência". }\end{array}$ \\
\hline SIC 14 & $\begin{array}{l}\text { "Não, pois o dinheiro não pode comprar tudo na vida muito menos amizade e } \\
\text { relacionamento afetivo". }\end{array}$ \\
\hline SIC 35 & $\begin{array}{l}\text { "Não interfere porque ter dinheiro ou não, não muda o que cada pessoa é de verdade } \\
\text { tanto no seu caráter quanto outras qualidades". }\end{array}$ \\
\hline
\end{tabular}

Fonte: Dados do Estudo (2015) 
Bertuzzi et al. (2007 p. 23) em estudo feito com adolescentes pobres encontraram percepções semelhantes pois revelam que os quando são questionados sobre a pobreza ou sobre o lugar onde moram os mesmos se colocam como desprezados e discriminados. "Tudo é a vila! Assalto? É na vila! Mataram? Foi na vila! Roubaram? Foi na vila...". E algumas vezes também se sentem prejudicados quanto a possibilidade de conseguir um emprego. E aí entra o outro/diferente: "Ele não trabalha porque é filhinho de papai. Eu não trabalho porque não tenho oportunidade" (comparando-se com um rapaz dito rico). "Se tu falas que mora em vila, já estão te olhando assim... Quando vou falar onde eu moro, já nem digo na vila, digo no bairro".

Os adolescentes que afirmam que a pobreza interfere nos relacionamentos interpessoais por vezes se sentem vulneráveis pela questão de não possuírem dinheiro suficiente para possuir o que para eles é sinônimo de uma condição de vida melhor e isso é explicado por Abramovay (2002) apud Bertuzzi et al. (2007 p.19) onde diz que "a vulnerabilidade social é definida como situação em que os recursos e habilidades de um dado grupo social são insuficientes e inadequados para lidar com as oportunidades oferecidas pela sociedade" Tais oportunidades podem ser uma forma de elevar os níveis de bem-estar dos adolescentes ou também podem ser intercessores da diminuição das probabilidades de deteriorização das condições de vida.

Por fim os adolescentes foram questionados se é possível deixar de ser pobre e $88,5 \%$ disse que sim. Como exemplifica o gráfico 4 a seguir:

Gráfico 4 - Adolescentes que acreditam ser possível deixar de ser pobre

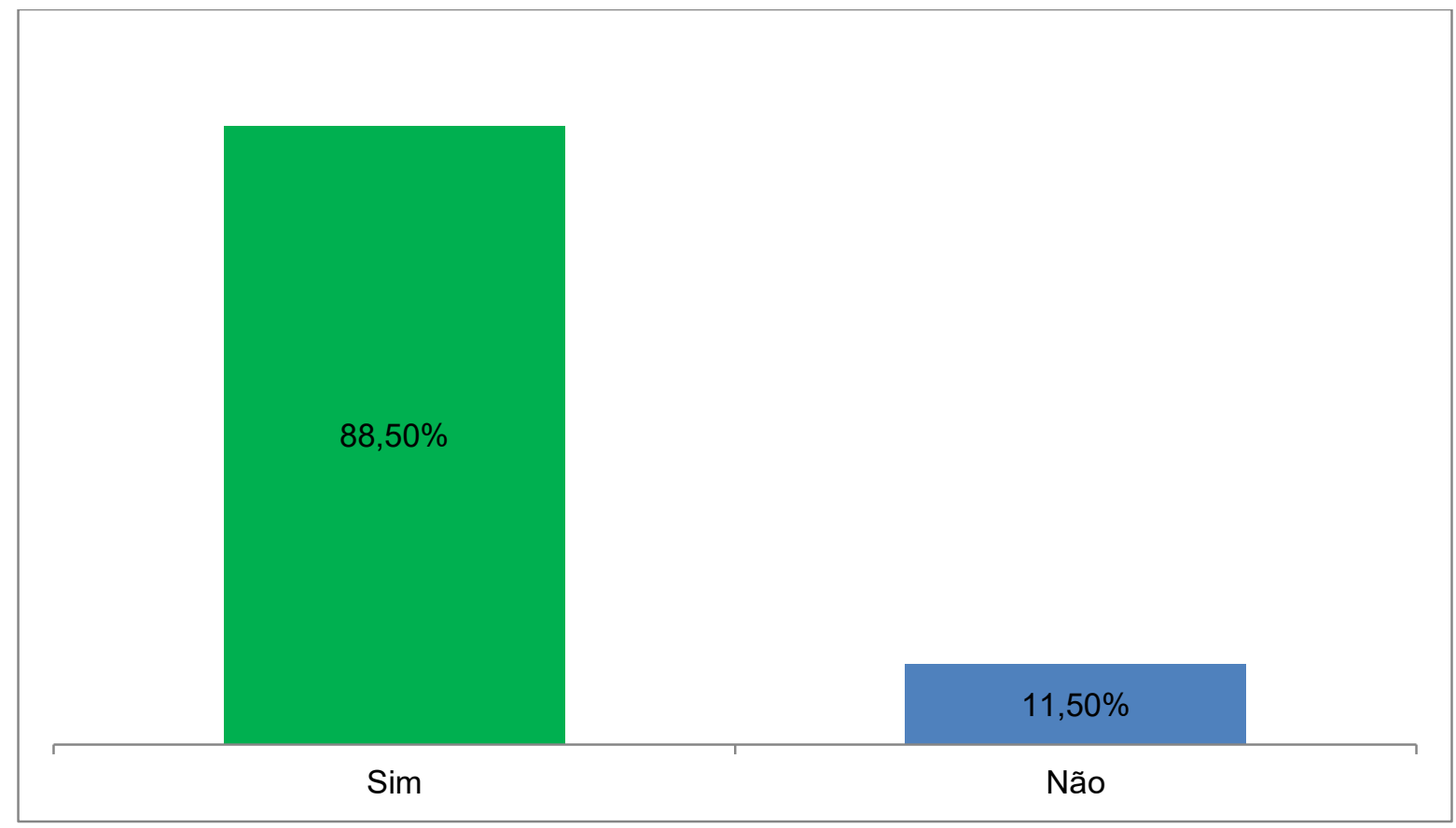

Fonte: Dados do Estudo (2015) 
Os adolesces que acreditam ser possível deixar de ser pobre associam esse fato ao esforço nos estudos e no seu trabalho, como exemplifica o quadro 3 :

Quadro 3 - Perspectiva dos adolescentes sobre como deixar de ser pobre

\begin{tabular}{|l|l|}
\hline SIC & Verbalização \\
\hline SIC 12 & "'ESTUDO' palavra chave para um futuro melhor e com mais garantia" \\
\hline SIC 17 & "Se esforçando, estudando principalmente, tentando arrumar um bom emprego". \\
\hline SIC 23 & $\begin{array}{l}\text { "Procurando aperfeiçoar-se fazendo cursos, estudando para que possa ter uma posição } \\
\text { melhor no mercado de trabalho". }\end{array}$ \\
\hline SIC 34 & "Trabalhando e aos poucos construindo objetivos para a vida". \\
\hline
\end{tabular}

Fonte: Dados do Estudo (2015)

Estivill (2003 p.1) destaca que "em todo o mundo, milhões de pessoas sobrevivem submetidas à pobreza e à exclusão social e é pouco provável que estas condições desapareçam nos próximos anos". A partir desse pressuposto pode-se identificar que mudar a situação social vai muito além do esforço pessoal e que depende muito da condição em que a sociedade se encontra.

Melsert e Bock (2015) afirmam que:

o esforço e o sucesso do pobre, oculta-se a certeza de um destino sofrido; quando se afirma o inevitável sucesso do rico, oculta-se a certeza do jogo de cartas marcadas. A desigualdade é nossa conhecida, mas preferimos não apresentá-la. Acreditamos que os jovens tenham consciência da desigualdade que marca nossa sociedade, mas que se distanciam dela (2015, p.786-787)

Em pesquisa Nascimento, Sarubbi e Souza (2009) verificaram que a ideia do esforço pessoal está presente do discurso de quem quer mudar sua condição de vida, mas ao mesmo tempo as pessoas sabem que só o esforço pessoal não basta, porém não deixam de se esforçar.

\section{CONSIDERAÇÕES FINAIS}

Em um primeiro momento é importante ressaltar que os adolescentes entrevistados que dizem saber o que é pobreza veem a mesma apenas como falta de dinheiro e bens materiais, desprezando a falta de cultura e liberdade que essa condição social pode trazer.

Pensar que é possível deixar de ser pobre para alguns está relacionado com o esforço próprio e suas iniciativas para mudar essa situação, mas para uma parte destes adolescentes ainda está relacionado ao pensamento cartesiano de que o governo é quem precisa tomar a iniciativa de fazer mudanças e melhorar a condição de vida dos menos favorecidos, atuando com benefícios e "ajudas financeiras" para os que necessitam. 
Em alguns discursos foi possível presenciar o interesse dos adolescentes em buscar um conhecimento técnico para atuar no mercado de trabalho, enfatizando que isto vem a ser um diferencial na busca de um emprego melhor e consequentemente de uma condição de vida melhor, mas que ainda está relacionada com a renda constituinte do orçamento familiar.

Mais da metade dos adolescentes entrevistados encontra-se trabalhando atualmente, alguns destes não moram mais com os pais, e o salário que recebem é para se manterem financeiramente sozinhos fora de casa. Os que ainda estão inseridos no núcleo familiar participam do orçamento contribuindo assim para a estabilidade financeira.

Os dados obtidos na pesquisa revelam que as afirmações e constatações dos adolescentes participantes do estudo abrem margem para novos estudos na área da Psicologia Social, como por exemplo, a ideia que os mesmos possuem sobre os programas sociais oferecidos pelo governo e de que maneira estes podem influenciar na mudança de sua condição social. Outro ponto a ser estudado é a compreensão do adolescente frente à privação da cultura e liberdade que a pobreza acarreta. E por fim adentrar ainda no entendimento que o adolescente possui sobre a condição social da família nuclear e a perspectiva da condição social na constituição de uma nova família.

\section{REFERÊNCIAS}

ARRUDA, Angela. Teoria das Representações Sociais de Gênero. Cadernos de Pesquisa, Rio de Janeiro, v. 1, n. 117, p.127-148, 01 nov. 2002. Disponível em: $<$ http://www.scielo.br/pdf/cp/n117/15555.pdf>.

BERTUZZI, Letícia D. et al. Intervenção na condição de vulnerabilidade social: um estudo sobre a produção de sentidos com adolescentes do programa do trabalho educativo. Estudos e Pesquisas em Psicologia, Rio de Janeiro, v. 1, n. 7, p.17-27, jan. 2007. Semestral.

CRESPO, Antônio Pedro Albernaz; GUROVITZ, Elaine. A Pobreza como um Fenômeno Multidimensional. Rae - Eletronica, São Paulo, v. 1, n. 2, p.1-12, 30 jul. 2002. Mensal. Disponível em: <http://www.scielo.br/pdf/raeel/v1n2/v1n2a03.pdf>.

ESTIVILL, Jordi. Panorama da luta contra a exclusão social: conceitos e estratégias. Genebra, Bureau Internacional do Trabalho, Programa Estratégias e Técnicas contra a Exclusão Social e a Pobreza, 2003. Disponível em: <http://www.ilo.org/public/portugue/region/eurpro/lisbon/pdf/panorama.pdf>

LOPES, José Rogério. "Exclusão Social" e Controle Social: Estratégias Contemporâneas de Redução da Sujeiticidade. Universidade do Vale do Rio dos Sino. Psicologia \& Sociedade, v. 18, n. 2, p. 13-24; maio/ago. 2006 
MAAKAROUN, Marília de Freitas. Adolescência: uma reedição da infância. Saúde de Jovens, 18 nov. 2006. Disponível em: <http://www.saudedejovens.com.br/ adolescencia-uma-reedicao-da-infancia/>.

MACÊDO, Edison Ferreira de. Criança, adolescência e pobreza na contemporaneidade. Fênix: Revista de História e Estudos Culturais, Paraíba, v. 1, n. 11, p.1-20, 2014. Semestral.

MELSERT, Ana Luísa de Marsilllac. BOCK, Ana Merces Bahia. Dimensão subjetiva da desigualdade social: um estudo de projetos de futuro de jovens ricos e pobres.

Educ. Pesqui., São Paulo, v. 41, n. 3, p. 773-790, jul./set. 2015

NASCIMENTO, Leda Souza do; SARUBBI, Maria Renata Menezes; SOUZA, Paula Pimenta de. A dimensão subjetiva da desigualdade social: um estudo sobre a dimensão subjetiva da vivência da desigualdade social na cidade de São Paulo. TransFormações em Psicologia, São Paulo, v. 2, n.1, 2009. Disponível em:<http://pepsic.bvsalud.org/scielo.php?script=sci_arttext\&pid=S2176106X2009000100002\&lng=pt\&nrm=iso>.

MOSCOVICCI, Serge. Representações Sociais: investigações em Psicologia Social. 2. ed. Petropolis: Vozes, 2003. 403 p.

OLIVEIRA, Márcio S. B. S. de. Representações sociais e sociedades: a contribuição de Serge Moscovici. Rev. bras. Ci. Soc. v.19, n. 55, p. 180-186, 2004.

<http://dx.doi.org/10.1590/S0102-69092004000200014>.

PAPALIA, Diane E.; OLDS, Sally Wendkos FELDMAN, Ruth Duskin.

Desenvolvimento físico e cognitivo do adolescente. In: PAPALIA, Diane E.

Desenvolvimento humano. 12.ed. Porto Alegre: Artmed, 2013. Cap. 11. p. 379444.

SANTANA, Sílvia Aparecida Santos de. A vulnerabilidade social uma questão da psicologia social. Neurociências: Psicologia, São Paulo, v. 4, n. 8, p.187-248, out. 2012. Trimestral.

VINHAIS, Henrique Eduardo Ferreira. Ensaio sobre a Redução da Pobreza no Brasil: Mensuração e Determinantes. 2006. 158 f. Dissertação (Mestrado) - Curso de Economia, Universidade de São Paulo, São Paulo, 2006. Disponível em: $<w w w . t e s e s . u s p . b r>$.

WLODARSKI, Regiane; CUNHA, Luiz Alexandre. Desigualdade Social e Pobreza como Consequências do Desenvolvimento da Sociedade. In: IX SIMPÓSIO INTERNACIONAL PROCESSO CIVILIZADOR TECNOLOGIA E CIVILIZAÇÃO. 2005, Ponta Grossa. Ponta Grossa: UEPG. p. 1 - 10.

WOLECK, Aimoré. O trabalho, a ocupação e o emprego: uma perspectiva histórica. Revista de Divulgação Técnico-científica do Instituto Catarinense de PósGraduação, p. 01 - 15, 01 jan. 2002. 
Representações sociais da pobreza para adolescentes de um município do interior do estado de Santa Catarina

Artigo recebido em: 22/11/2015

Artigo aprovado em: 11/12/2017

Artigo publicado em: 20/12/2017 